Neurosurg Focus 13 (2):Article 13, 2002, Click here to return to Table of Contents

\title{
Discography interpretation and techniques in the lumbar spine
}

\author{
Frank J. Tomecek, M.D., C. Scott Anthony, M.D., Chris Boxell, M.D., \\ AND JENNIFER WARREN, C.N.S. \\ Department of Neurosurgery, University of Oklahoma College of Medicine, Tulsa, Oklahoma
}

\begin{abstract}
The authors provide an indepth analysis of discography, a provocative diagnostic tool to determine the origin of low-back pain. Injecting the intervertebral disc with radiopaque dye provides physicians with several useful pieces of information. First, the modality provides radiographic evaluation of the integrity of the nucleus pulposus and anular rings to determine tears or other lesions that could be creating low-back pain. Second, and very important, is its measure of disc nociception. A normal disc should not cause pain when injected; however, a disc that is physiologically compromised can mimic the pain previously experienced by a patient. The authors review the indications, technique, and interpretation of discography to allow a better understanding of when to use this diagnostic test and what to do with the results.
\end{abstract}

KEY WORDS • discography - low-back pain - lumbar spine

Lumbar discography is an invasive diagnostic procedure that involves, under fluoroscopic guidance, the puncturing of a disc for the instillation of iodinated contrast into the nucleus pulposus. This procedure provides direct radiographic information concerning the nuclear morphological features and integrity of the vertebral endplates and anulus. The measured contrast injection allows determination of intradiscal pressures. Measurements of the opening pressures and pressure endpoints, where no further contrast can be injected, as well as the measurements of the associated volumes of contrast injected in the disc, can be used to demonstrate the integrity of the inner and outer anuli. The resulting changes in the volume and pressure produce direct stimulation of the disc. A patient's response to this stimulation is a measure of disc nociception. Therefore, the purpose of this procedure is not only to define the anatomical architecture of the internal disc but to determine whether a particular disc is painful. This provocative response to injection can be useful in identifying the pain generator and assist in the assessment of patients with severe disabling back pain syndromes.

Abbreviations used in this paper: $\mathrm{CT}=$ computerized tomography; HIZ = high-intensity zone; MR = magnetic resonance; PLL = posterior longitudinal ligament; $\mathrm{SAP}=$ superior articular process.

\section{PROVOCATIVE DISCOGRAPHY}

\section{Historical Background}

Puncture of the intervertebral disc for diagnostic purposes was first performed in Scandinavia by Lindgren, who presented a case of a normal disc injected with contrast in 1941. In 1948 Lindblom $^{37}$ was the first to publish in vitro studies on discography; he used a posterior transdural entry with a water-soluble agent. In 1948 Hirsch $^{30}$ used this procedure to diagnose the level of painful disc lesions in patients with lumbago and sciatica. Discography was developed at a time when oil-based myelography was associated with an unacceptable high false-negative rate, and discography was viewed as a viable alternative to myelography.

The diagnostic parameter of the procedure was the pain response (provocative disc injection). In the same year, Lindblom, ${ }^{37}$ encouraged by the work of Hirsch, ${ }^{30}$ modified the technique by injecting contrast material to visualize radial tears of the anulus in the intervertebral discs. The diagnostic criteria were thus expanded to include the radiographic appearance of the disc and patient response to the injection.

Discography was first performed by Wise, et al., ${ }^{67}$ in the United States in the early 1950s at the Cleveland Clinic. In 
the early 1960s, Collis and Gardner ${ }^{19}$ reported on 1000 patients and asserted that discography was superior to myelography in the evaluation of lumbar disc disease. Feinberg ${ }^{20}$ reported on over 2000 patients, describing patterns on abnormal discograms that remain valid today. Cloward ${ }^{15,17}$ researched discography exhaustively, used it extensively, and published results obtained in thousands of cases. In fact, Cloward's efforts provided one of the precipitating forces in the evaluation of cervical discography. ${ }^{16}$ Many of these physicians and others considered anular tears to be significant lesions, and back and leg pain could not be explained by nerve compression alone.

Despite the encouraging reports published by several authors regarding discography's usefulness after 50 years, considerable controversy remains concerning its indications, value, interpretation of its findings, and, for some, even its safety. Its validity as a test was first challenged by Holt $^{31}$ in 1968. He reported on a series of 30 prison inmates without a history of low-back pain; discography demonstrated abnormal painful discs in $36 \%$. Holt concluded that the procedure was sensitive but not specific in identifying the disc as a pain generator in patients with chronic low-back pain.

Although there can be no dispute that false-positive and, rarely, false-negative results do occur in any diagnostic test, including discography, the details of Holt's technique and interpretation of his study ${ }^{31}$ were believed by many authors to be flawed and biased. Walsh, et al. ${ }^{64}$ and Simmons, et al., ${ }^{58}$ critiqued Holt's study. They pointed out Holt's selection bias for exclusion of $23 \%$ of the injected discs, which were judged invalid because of technical difficulties. In addition, April and Bognuk ${ }^{2}$ critiqued Holt's study, asserting that some of his "successful" discograms may have, in fact, reflected anular injections, which are known to be painful and can lead to inaccurate false-positive interpretations.

In 1990, Walsh, et al. ${ }^{64}$ performed a controlled prospective study to establish the specificity of lumbar discography by comparing results in 10 asymptomatic volunteers with those determined in seven patients with chronic lowback pain. In their study, the discogram was defined as "positive" only when substantial pain was associated with an accurately placed injection in the nucleus (provocation). Based on this criterion, there were no positive discograms demonstrated in the asymptomatic individuals (a false-positive rate of $0 \%$ and a specificity of 100\%). Walsh, et al., attributed the following factors to the improved validity of discography for identifying painful discs: 1) advances in fluoroscopic guidance for accurate needle placement; 2) the use of postdiscography CT scanning for the evaluation of the accuracy of intranuclear injection; and 3) the use of a less toxic contrast agent. By incorporating fluoroscopy and postdiscography CT scanning, these authors helped to establish the standards of modern-day discography. The authors of many other studies have subsequently demonstrated the combination of discography and postdiscography CT scanning to be quite sensitive in delineating disc degeneration and in pinpointing painful pathological discs. ${ }_{50,53,57,9,10,14,22,24,27,32,41,43,46,47}$, $50,53,57,59,61,63$

\section{Discogenic Pain}

Backache is a common ailment and its origin has often been elusive, especially when a herniated disc or severe spinal stenosis is absent. Abnormalities of the intervertebral disc and internal disruption of the anulus have long been considered potential sources of low-back pain. To be a source of pain, a structure must be innervated. There have been controversies regarding the innervation of the disc and whether the cause for pain was biomechanical or chemical. It is believed that the pain generated by discography occurs when anular fissures or nuclear herniations extend into the outer third of the anulus fibrosis. ${ }^{46}$ Nerve endings from branches of the sinuvertebral nerves, the gray rami communicantes, and the lumbar ventral rami consistently innervate the outer third of the dorsal, lateral, and ventral aspects of the anulus respectively ${ }^{7}$ (Fig. 1). In histological and immunocytochemical studies authors have documented the presence of a variety of nerve endings in the outer anulus. Neurotransmitters associated with nociception have been detected in the anulus and PLL. ${ }^{51}$ Therefore, the disc does have the anatomical substrate to be a pain generator.

The authors of histochemical studies have shown that nerve endings in the anulus contain peptides, such as calcitonin gene-related peptide, vasoactive intestinal peptide, and substance P. These peptides have been shown to be associated with nociception. ${ }^{1,34,65}$ The "concordant" discography-provoked pain response may relate to the stimulation of these nociceptive nerve endings by enzymes, such as phospholipase A2, and nuclear degradation products. ${ }^{66}$ Additionally, there is evidence that an autoimmune response to the nucleus pulposus and its degradation products may incite an inflammatory response in the epidural space, dura mater, and nerve roots, thereby also triggering nociceptive nerve endings. ${ }^{5,26,42,48,49,60}$ Heggeness and Doherty ${ }^{29}$ have documented endplate deflection during intradiscal injection, which could explain a mechanical component for discogenic low-back pain and the concordant pain of discography. ${ }^{29}$

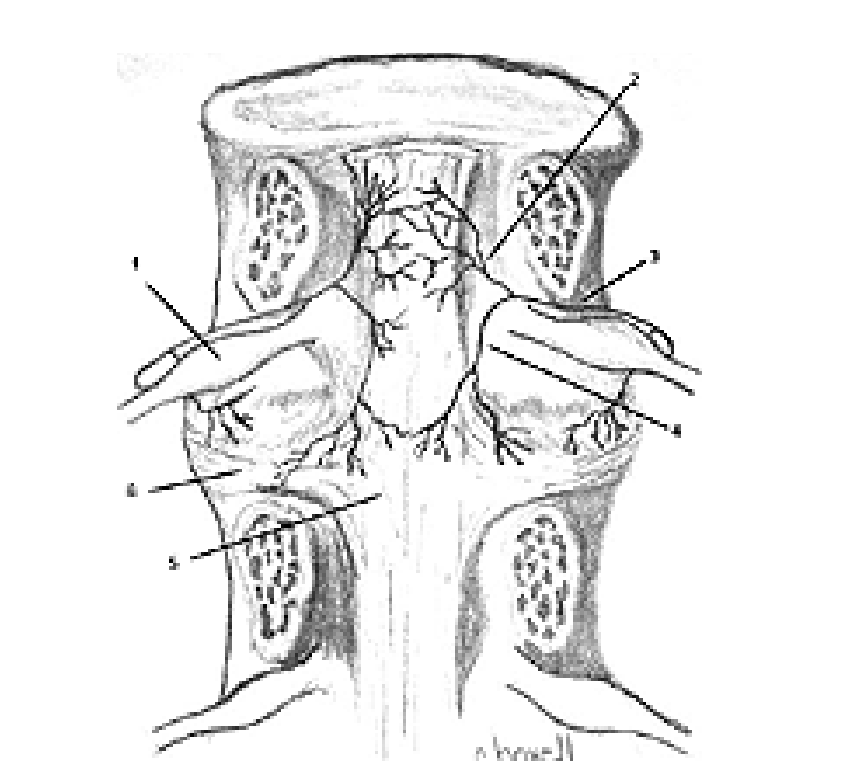

Fig. 1. Innervation of the PLL and anulus. $1=$ dorsal root ganglion; 2 = ascending branch of the sinuvertebral nerve; $3=$ sinuvertebral nerve; $4=$ descending branch of the sinuvertebral nerve; $5=$ PLL; $6=$ disc anulus. 
The International Association for the Study of Pain defines lumbar discogenic pain and internal disc disruption in its classification of spinal and radicular pain syndromes. ${ }^{44}$ Lumbar discogenic pain and internal disc disruption are defined as lumbar pain, with or without referred pain, stemming from an intervertebral disc. Discogenic pain is caused by internal disruption of the normal structural and biochemical integrity of the symptomatic disc. Discography is necessary to establish and confirm these diagnoses. In one prevalent study it has been reported that discogenic pain was demonstrated in 39\% of patients with severe chronic low-back pain studied in tertiary practices. ${ }^{51}$

\section{Discography-Related Indications}

Magnetic resonance imaging emerged in the 1980s as the procedure of choice to detect and characterize disc lesions ${ }^{54}$ It is a safe, noninvasive, nonpain-inducing test. It has been shown to be very sensitive in detecting abnormalities in disc morphology, and there is significant controversy as to whether discography adds any diagnostic data greater than those provided by the noninvasive MR imaging study. ${ }^{52}$ Although plain radiography, myelography, CT scanning, and MR imaging all may demonstrate pathological degenerative changes of the spine, however, none of these studies alone or in combination can specifically identify the disc as a pain generator. Certainly, when the clinical problem is predominantly caused by radicular pain and suspected neural compression, MR imaging is indicated and, together with appropriate clinical findings, is usually sufficient for diagnostic purposes. Discography is not indicated or necessary to confirm the unequivocal presence of herniated discs that coincide with findings on clinical examination.

The primary indication for lumbar discography is chronic low-back pain with or without radicular pain in the absence of MR imaging-documented neural compression. Since the advent of the "open MR imager" for claustrophobic patients, the quality of the images has been variable. Discography can be used for identifying disc lesions and pain generators when MR images are equivocal. Discography is also indicated in the following scenarios: when clinical findings point to one level or one side and myelography or MR imaging indicates a different level, or when the disc protrusion is asymmetrical to the contralateral side of the patient's symptoms (Fig. 2). In some cases, far-lateral disc herniations may be confused with nerve sheath tumors or hematomas. Again, discography is indicated to resolve these diagnostic dilemmas.

Discography is also useful in evaluating discs adjacent to previously fused lumbar segments. In cases in which a prior instrumentation-assisted lumbar fusion has produced a good result but in which the patient eventually develops recurrent back pain, these patients are good candidates for discography because MR imaging studies are often too considerably distorted by artifacts to demonstrate properly the discs adjacent to instrumented fusions. This is especially true in cases of lumbar fusion in which the hardware is composed of stainless steel (Fig. 3).

Because it is a dynamic test, myelography is excellent for assessing the stability of the spine, especially in the case of spondylolisthesis. Magnetic resonance imaging is also useful in detecting clearly pathological stenosis and spondylolisthesis. Discography in these instances is indicated as a valuable adjunct for the study of equivocal MR imaging or myelographic findings adjacent to clearly pathological levels considered for fusion. Discs that are morphologically abnormal but cause no pain may be excluded from the fusion site ${ }^{46,52}$ (Fig. 4).

Discography may also be indicated to assist in the diagnosis of painful pseudarthrosis. ${ }^{52}$ Discography can be performed in patients who have undergone attempted posterolateral lumbar fusion in which posterior lumbar interbody fusion has not been performed. A positive discogram at the "fused" level may identify a persistently painful disc, suggesting the need for disc removal and interbody fusion.

In addition to its positive uses of identifying offending lumbar segments and directing surgical treatment, discography can be indicated to identify patients who are poor surgical candidates. A patient's coping mechanism and pain tolerance often becomes very evident during discography. Some patients exhibit profound intolerance to mild nociceptive stimuli, even when narcotic agents have been administered and sedation induced. Patients in whom profound pain intolerance is demonstrated during discography are often very difficult to manage postoperatively and are more prone to developing chronic pain syndromes and failed outcomes. Discography can also be used to identify patients with psychological abnormalities or those for whom secondary gain issues may be at stake. Provocation of pain at levels that are morphologically normal on postdiscography CT scanning and MR imaging is a contraindication for surgical (or other invasive) intervention. ${ }^{52}$ In addition, pain provoked at multiple levels in combination with equivocal morphological abnormalities often suggests the presence of secondary gain or psychological factors that are associated with poor surgical outcomes. Warranting discussion is the special condition in which there are concordantly positive discograms of multiple levels that are radiographically abnormal. In this circumstance, careful evaluation of potential secondary gain issues and further psychological testing may be necessary before treatments can be recommended.

Review of the literature suggests that successful outcomes after surgery for single-level disease can be expected in $75 \%$ or more of the cases. . $^{3,4,11,18-20,23,24,35,57,61,68}$ Obvi-

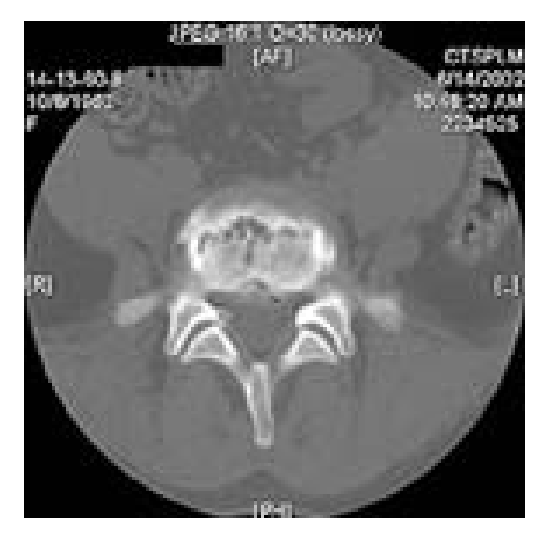

Fig. 2. Postdiscography CT scan demonstrating a severe degenerative disc with multiple anular tears and extravasation of contrast. 


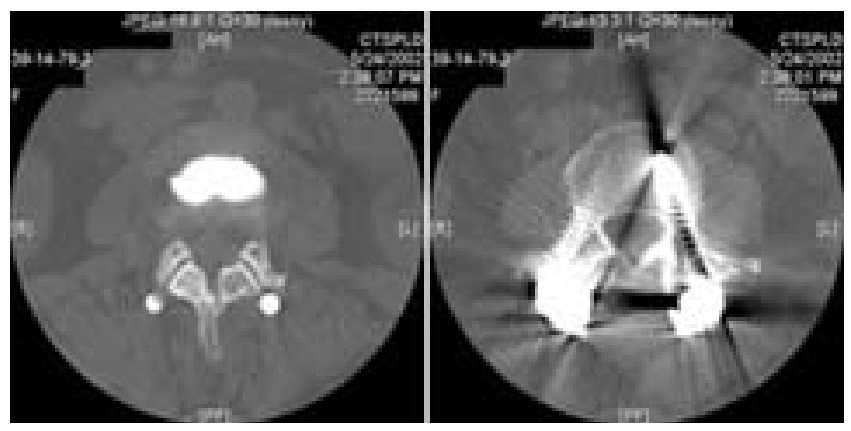

Fig. 3. Left: Normal radiographic appearance of lumbar disc adjacent to lumbar fusion. Right: Postdiscography CT scan obtained through the fused level.

ously, however, larger multilevel operations have higher risks of complications in addition to higher pseudarthrosis rates, which are associated with chronic pain syndromes and treatment-related failures. Risk factors for bone healing such as smoking, diabetes mellitus, and chronic steroid medication use should carry special importance when evaluating patients with multilevel conditions. The presence of one or more behavioral or physiological risk factors should emphasize discography's screening ability - that is, as a diagnostic test to identify patients with multilevel disease and with the potential for eliminating surgical treatment in this high-risk group.

\section{Discography-Related Caveats}

Recurrent disc herniations, especially when associated with significant epidural and perineural scar tissue, can present as diagnostic dilemmas. Magnetic resonance imagingwith and without contrast can identify recurrent disc herniations, ${ }^{10,22,39,40,45,54,56}$ but often the diagnosis remains in question. Discography has been indicated, and often used, to clarify the significance of recurrent pain syndromes in patients who have undergone discectomies. In a prospective randomized study of the discography-provoked pain response in symptomatic and asymptomatic patients after limited discectomy, Carragee ${ }^{11}$ showed that discography can have very high false-positive results and be of limited usefulness. Asymptomatic patients with normal psychometric test results and who previously under1went lumbar discectomy experienced significant pain when their previously operated discs were injected with contrast $40 \%$ of the time. ${ }^{13}$ Symptomatic patients with normal psychometric test results experienced postinjection pain $63 \%$ of the time. In patients with abnormal psychological profiles, a significantly higher rate of painpositive disc injections was demonstrated than in either asymptomatic volunteers or symptomatic individuals with normal psychological profiles. ${ }^{11}$ This identifies another subset of patients in whom discography alone is used to determine if the necessity of surgery is ill advised.

The interpretation of discographic results in elderly patients ( $>55$ years of age) should also be performed with caution. In a prospective study on the value of discography in different age groups, Vanharanta, et al. ${ }^{62}$ found that the proportion of severely radiographically documented degenerated but painless discs increases with age. Therefore, discography may have limited usefulness in the elderly population.

\section{LUMBAR DISCOGRAPHY TECHNIQUE}

Preoperative instructions should be given to the patient. A discussion of discography-related risks should include the following: disc infection, superficial infection, bruising and swelling at the site, and flare up of pain. Other risks of dural procedure, post-dural puncture headache, neural injury, paralysis, and death should be also be discussed.

It is important to ask the patient about the exact location of his/her pain. The patient should complete a pain diagram. The amount of back pain compared with buttock pain and leg pain should be noted. A patient-related pain score should be determined prior to discography for comparison with one assessed after disc injection.

An intravenous line as well as normal saline-containing fluids should be started. Any allergy to contrast should be addressed, as should as the need for prophylactic medications such as Benadryl and a steroid agent. The patient is given a prophylactic 900-mg dose of Ancef, and the remaining $100 \mathrm{mg}$ should be included in the contrast.

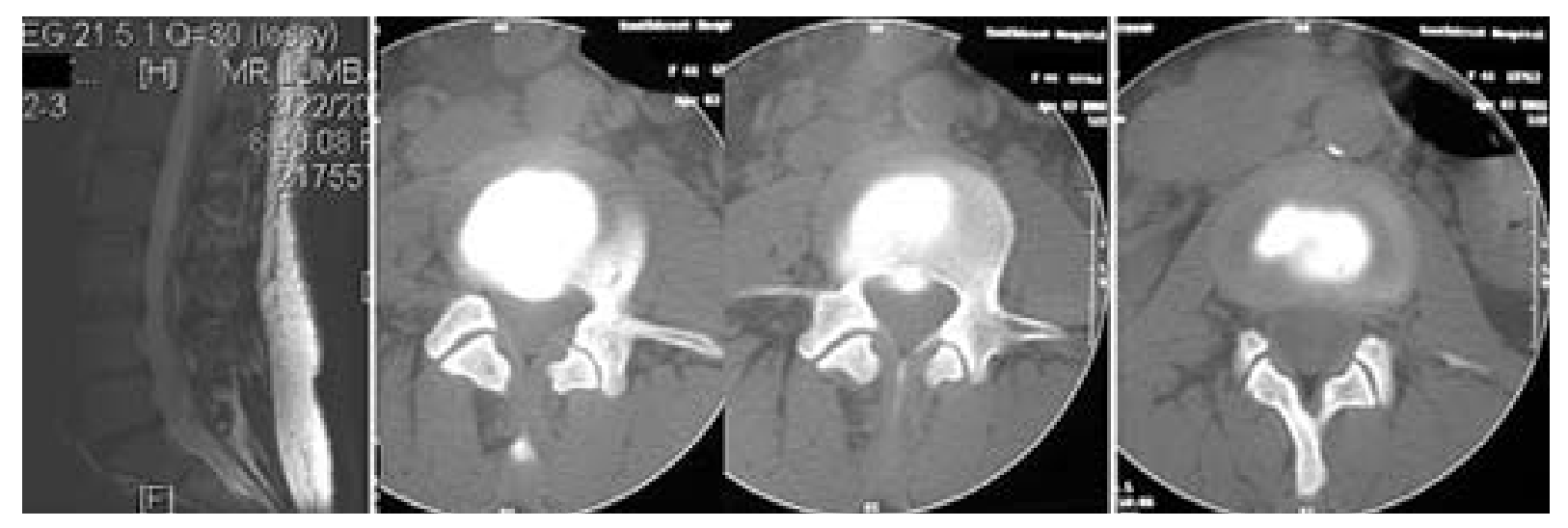

Fig. 4. Left: Sagittal MR image demonstrating significant collapse of L4-5 and L5-S1 intervertebral discs with degenerative changes of the endplates. Center: Postdiscography CT scan of L3-4 revealing anular tears and internal disc disruption. Right: Postdiscography CT scan demonstrating a normal (L2-3) disc. 
Positioning of the patient is important. The difficulty of performing discography in the lumbar spine can be greatly reduced with the appropriate positioning. Some discographers prefer to place the patient in a lateral or prone position. A position in which the patient's body is slightly oblique and at a $45^{\circ}$ angle to the bed and rotated forward is often optimum. This allows for less movement during the procedure (a drawback of a lateral position). There is no need to use restraints. Positioning the patient at a $45^{\circ}$ angle allows much better visualization of the lumbosacral junction as well as for needle placement, reducing the chance of striking the iliac crest on needle insertion.

Blood pressure and pulse oximetry should be monitored.

Intravenous sedation is given, but the patient should be awake and coherent so that adequate feedback information is obtainable. Typically, the patient receives intravenous Versed with an opioid, usually Demerol or morphine. The patient should have a recollection of the discographic procedure. This is important because the referring surgeon will often ask the patient procedure-related questions at the follow-up visit.

The back is prepared, typically with Betadine, and draped. A mask, hat, and surgical gown are used to avoid further the chance of infection.

The fluoroscope is then positioned. Approaching the lumbosacral disc requires a cranial tilt of the $\mathrm{C}$-arm at roughly $45^{\circ}$. The goal of tilting the $\mathrm{C}$-arm is to obtain good visualization of the disc space. The endplates should be "crisp" or on the edge. At this point, the C-arm is tilted so that the SAP is in the midportion of the disc space. At this point, there should be a triangular opening to approach the disc. The SAP forms this triangle medially, laterally by the iliac crest and superiorly by the L-5 endplate.

The lumbar discs superior to L5-S1 are typically easier to enter because the iliac crest lies lower and is typically not obstructing the view of the disc space. Also less cranial tilt is needed with the $\mathrm{C}$-arm as one progresses to adjacent discs. Typically, a straight anteroposterior view is sufficient for the L3-4 disc and the L2-3 disc will actually have somewhat of a caudad tilt. For all injected discs, the SAP should be at the midpoint of the disc with the edges of the endplates clearly visualized.

At this point, a local anesthetic (1\% lidocaine) is infiltrated to the skin and musculature. The SAP should not be anesthetized because this may spread local anesthetic at the foramen and margin of the disc, increasing the chance of a false-negative response on discography. An appropriate-sized 18-gauge spinal needle is then placed through the musculature. This needle is placed via a right paramedian approach. Under fluoroscopy, this needle should strike the SAP. Typically, a 3.5-inch needle is sufficient. Once contact is made with the SAP, the needle is walked slightly lateral and at a midpoint between the endplates. Once the needle is clear of the SAP, the stylet is removed.

At this point, a 22-gauge spinal needle (typically 6 inches long) is inserted via the introducer needle. Before insertion a gentle curve is formed with the needle manually. The needle must pass lateral to the SAP yet medial to the exiting nerve root. Resistance and back pain will be noted on passing it through the anulus. Lancinating pain into the extremity likely suggests contact with the nerve root, at which point the needle is redirected. The use of a two-nee- dle technique reduces the risk of disc infection. ${ }^{12}$ Once penetration into the disc occurs, anteroposterior and lateral images of the disc are obtained. The needle tip should be in the center of the disc space on both of these views. Any deviation leads to the risk of anular injection of contrast.

Water-based iodine contrast (Isovue 300 or Omnipaque) is mixed with the remaining Ancef and prepared for injection. Intradiscal antibiotics may further reduce the risk of infection.

The use of a pressure syringe is suggested. The information obtained includes opening pressure, pressure at onset of pain, and maximum pressure. Opening pressure is noted when dye is appreciated within the disc space. The correlation of opening pressure and pressure at pain onset is important, potentially influencing surgical technique. The integrity of the disc can be determined by assessing the amount of pressure it can hold. An incompetent disc will "bleed off" pressure quite rapidly because of leakage of contrast. A typical "negative" or nonpainful lumbar disc should be able to hold pressure up to at least $90 \mathrm{~mm} \mathrm{H}_{2} \mathrm{O}$.

The disc morphological characteristics, presence of a complete or partial tear, and any epidural spread of contrast should be noted. A detailed discussion of the pain produced at the time of injection is mandatory. Questions include the location, intensity, and quality of pain. The patient should quantify his pain on a scale of 0 to 10 . The pain should be classified as strongly concordant, partially concordant, or disconcordant.

Videotaping during discography is helpful-both of the disc injection phase and the patient's facial expression. This can help the surgeon to determine the response at the time of the injection (Click here to view Video Clip).

Pain mannerisms are important to note. Does the patient have good or exaggerated pain mannerisms? Will this suggest poor surgery-related outcome after lumbar fusion?

The suspected painful disc(s) should be injected last. A local anesthetic should not be injected into a painful disc after the contrast injection before proceeding to an adjacent disc. Any extravasation of local anesthetic to adjacent discs risks yielding a false-negative result. A normal and nonpainful (control) disc should be pursued within reason (Fig. 5).

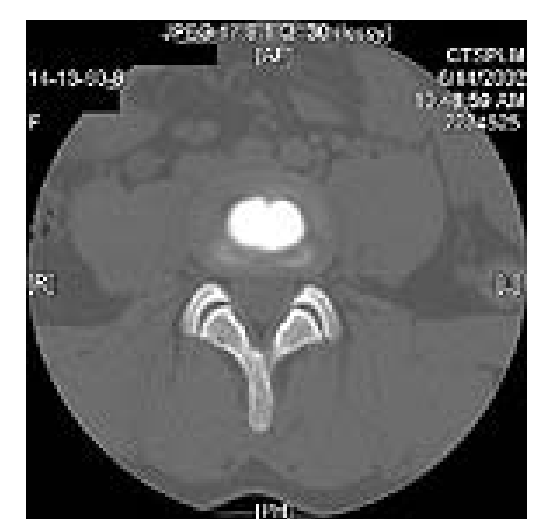

Fig. 5. Postdiscography CT scan of normal nucleus and intact anulus. 


\section{CONCLUSIONS}

Since its introduction in 1948, the direct injection of contrast medium into the intervertebral disc has been widely investigated. The results of these studies, and the public opinion regarding its validity as a predictor of a patient's pain generator, remain controversial. Unfortunately, no adjunctive test, preceding or proceeding the advent of discography, has been shown consistently to identify the cause of nonradicular low-back pain. Nevertheless, when used in conjunction with MR imaging and other tests, as well as a careful history and physical examination, discography may be useful in evaluating equivocal cases in which patients suffer intractable, chronic, and disabling low-back pain.

As with any other invasive test, discography is measured by its safety and its diagnostic ability. Since its initial use as a diagnostic test, however, discography has also been expected to predict surgery-related outcome. Carragee, et al. ${ }^{12}$ performed a prospective study to assess the safety of discography. They concluded that lumbar discography is generally considered to be safe, with very rare complications of discitis and nerve injury. They also were able to answer a very pertinent question asked by physicians regarding the safety of this test: can discography cause long-term back symptoms in previously asymptomatic individuals? They concluded that no individual with normal psychometric test results suffered persistent pain after discography, whereas $40 \%$ of those with abnormal psychometric test results reported significant new lowback pain. Psychological test results and occupational disability strongly predicted continued pain after discography. Discography in individuals without low-back pain but with significant emotional and chronic pain problems may result in reports of significant back pain for at least 1 year after injection. Individuals in whom psychometric test results were normal reported no long-term back pain after discography. Therefore, not only is discography safe but it also can be used to identify potential problem patients unlikely to benefit from surgical intervention.

The knowledge of the relative ability of MR imaging to predict discography-related results is useful for the selection of diagnostic tests. If MR imaging findings correlate exactly with discographic results in predicting surgeryrelated outcomes, then an invasive diagnostic test such as discography would not be indicated. According to Bogduk, ${ }^{6}$ four MR imaging features correlate with discographic features in predicting concordant pain response, providing diagnostic confidence of approximately $80 \%$ : 1) severe disc space narrowing; 2) bone marrow intensity change; 3) severe loss of nucleus signal; and 4) the HIZ. ${ }^{6}$ Although valid, the first two of these characteristics occur too infrequently to be of routine diagnostic value. Only severe loss of nucleus signal and the HIZ constitute useful signs. Although they occur in only 25 and $20 \%$ of patients, respectively, their validity indicates that a diagnosis of low-back pain can be made on MR imaging in at least one of four patients with chronic low-back pain. Other studies place the prevalence of HIZ closer to $30 \% .^{2,28,55}$ In additional different studies, Lam, et al., ${ }^{36}$ and Ito, et al., ${ }^{33}$ found the presence of HIZ to be $87 \%$ sensitive as a predictor of a concordant pain response. Therefore, in the 70 to $80 \%$ of patients who suffer from chronic low-back pain but in whom no severe loss of nuclear signal or HIZ is demonstrated on MR imaging, discography remains a useful diagnostic tool. It is also apparent in the literature that a concordantly positive pain response is extremely rare in cases in which MR imaging has detected the presence of a normal disc. ${ }^{32,33,54,55,59}$ The use of discography should thus be limited to patients in whom MR imaging demonstrates abnormal findings that are nondiagnostic for internal disc disruption.

Finally, the true challenge of any diagnostic test is its ability to predict the outcome of patient treatment based upon the results of the test. Gill and Blumenthal ${ }^{23}$ performed a study in which they conducted both discography and MR imaging in efforts to predict patient outcome. They found that patients with discography-induced concordant pain and an MR imaging-documented abnormality fared well $75 \%$ of the time with single-level L5-S1 fusion. Patients in whom MR imaging revealed normal findings but in whom discography provoked concordant pain only had a favorable outcome $50 \%$ of the time. ${ }^{23}$ Colhoun and colleagues ${ }^{18}$ performed a similar study with discography alone to predict outcome. They reported an $89 \%$ favorable outcome in patients in whom discography provoked concordant pain responses as opposed to a $52 \%$ favorable result rate in those with radiographically documented abnormal findings and no pain or absent nonconcordant pain. Therefore, although it is not perfect, discography does have significant predictive value of patient's surgery-related outcomes. Discography also is unique in being the only provocative test available to diagnose pain generators. Thus, because it is relatively safe and sensitive in identifying painful discs and it has predictive value for surgery-related outcomes in some instances, it should remain a useful diagnostic tool in the spine surgeon's armamentarium in the assessment of internal disc disruption and degenerative disc disease.

\section{References}

1. Ahmed M, Bjurholm A, Kreicbergs A, et al: Neuropeptide Y, tyrosine hydroxylase and vasoactive intestinal polypeptide-immunoreactive nerve fibers in the vertebral bodies, discs, dura mater, and spinal ligaments of the rat lumbar spine. Spine 18: 268-273, 1993

2. Aprill C, Bogduk N: High-intensity zone: a diagnostic sign of painful lumbar disc on magnetic resonance imaging. Br J Radiol 65:361-369, 1992

3. Bernard TN Jr: Lumbar discography followed by computed tomography. Refining the diagnosis of low-back pain. Spine 15: 690-707, 1990

4. Birney TJ, White JJ Jr, Berens D, et al: Comparison of MRI and discography in the diagnosis of lumbar degenerative disc disease. J Spinal Disord 5:417-423, 1992

5. Bobechko WP, Hirsch C: Auto-immune response to nucleus pulposus in the rabbit. J Bone Joint Surg Br 47:574, 1965 (Reference unverified)

6. Bogduk N: Comment on Ito M, Incorvaia KM, Yu SF, et al: Predictive signs of discogenic lumbar pain on magnetic resonance imaging with discography correlation. Spine 23: 1252-1260, 1998

7. Bogduk N: The innervation of the lumbar spine. Spine 8: 286-293, 1983

8. Bogduk N, Tynan W, Wilson AS: The nerve supply to the human lumbar intervertebral discs. J Anat 132:39-56, 1981

9. Buirski G: Magnetic resonance signal patterns of lumbar discs 
in patients with low back pain. A prospective study with discographic correlation. Spine 17:1199-1204, 1992

10. Buirski G, Silberstein M: The symptomatic lumbar disc in patients with low-back pain. Magnetic resonance imaging appearances in both a symptomatic and control population. Spine 18: 1808-1811, 1993

11. Carragee EJ: Is lumbar discography a determinate of discogenic low back pain: provocative discography reconsidered. Curr Rev Pain 4:301-308, 2000

12. Carragee EJ, Chen Y, Tanner CM, et al: Can discography cause long-term back symptoms in previously asymptomatic subjects? Spine 25:1803-1808, 2000

13. Carragee EJ, Tanner CM, Khurana S, et al: The rates of falsepositive lumbar discography in select patients without low back symptoms. Spine 25:1373-1381, 2000

14. Castro WH, Jerosch J, Hepp R, et al: Restriction of indication for automated percutaneous lumbar discectomy based on computed tomographic discography. Spine 17:1239-1243, 1992

15. Cloward RB: Anterior herniation of a ruptured lumbar intervertebral disc. Arch Surg 64:457-463, 1952 (Reference unverified)

16. Cloward RB: Cervical discography: Technique, indications, and use in diagnosis of ruptured cervical discs. American Journal of Roentgenology 79:563-574, 1958 (Reference unverified)

17. Cloward RB: Multiple ruptured lumbar discs. Ann Surg 142: 190-195, 1955 (Reference unverified)

18. Colhoun E, McCall IW, Williams L, et al: Provocation discography as a guide to planning operations on the spine. $\mathbf{J}$ Bone Joint Surg Br 70:267-271, 1988

19. Collis JS Jr, Gardner WJ: Lumbar discography: an analysis of one thousand cases. J Neurosurg 19:452-461, 1962

20. Feinberg SB: The place of discography in radiology as based on 2,320 cases. AJR 92:1275-1281, 1964 (Reference unverified)

21. Ford LT, Key JA: An elevation of myelography in the diagnosis of intervertebral disc lesions in the low back. J Bone Joint Surg Am 32:257-266, 1950 (Reference unverified)

22. Gibson MJ, Buckley J, Mawhinney R, et al: Magnetic resonance imaging and discography in the diagnosis of disc degeneration. A comparative study of 50 discs. J Bone Joint Surg Br 68:369-373, 1986

23. Gill K, Blumenthal SL: Functional results after anterior lumbar fusion at L5-S1 in patients with normal and abnormal MRI scans. Spine 17:940-942, 1992

24. Greenspan A, Amparo EG, Gorczyca DP, et al: Is there a role for diskography in the era of magnetic resonance imaging? Prospective correlation and quantitative analysis of computed tomography-discography, magnetic resonance imaging and surgical findings. J Spinal Disord 5:26-31, 1992

25. Groen GJ, Baljet B, Drukker T: Nerves and nerve plexuses of the human vertebral column. Am J Anatomy 188:282-296, 1990

26. Grönblad M, Virri J, Tolonen J, et al: A controlled immunohistochemical study of inflammatory cells in disc herniation tissue. Spine 19:2744-2751, 1994

27. Grubb SA, Lipscomb HJ, Guilford WB: The relative value of lumbar roentgenograms, metrizamide myelography, and discography in the assessment of patients with chronic low-back syndrome. Spine 12:282-286, 1987

28. Hauser BO: Letter to the Editor. Spine 22:1538, 1997 (Letter) (Reference unverified)

29. Heggeness MH, Doherty BJ: Discography causes end plate deflection. Spine 18:1050-1053, 1993

30. Hirsch C: An attempt to diagnose the level of a disc lesion clinically by disc puncture. Acta Orthop 18:132-140, 1948 (Reference unverified)

31. Holt EP Jr: The question of lumbar discography. J Bone Joint Surg Am 50:720-726, 1968

32. Horton WC, Daftari TK: Which disc as visualized by magnetic resonance imaging is actually a source of pain? A correlation between magnetic resonance imaging and discography. Spine 17 (Suppl 6):S164-S171, 1992

33. Ito M, Incorvaia KM, Yu SF, et al: Predictive signs of dicogenic lumbar pain on magnetic resonance imaging with discography correlation. Spine 23:1252-1260, 1998

34. Kawakami M, Weinstein JN, Spratt KF, et al: Experimental lumbar radiculopathy. Immunohistochemical and quantitative demonstrations of pain induced by lumbar nerve root irritation of the rat. Spine 19:1780-1794, 1994

35. Kozak JA, O'Brien JP: Simultaneous combined anterior and posterior fusion. An independent analysis of a treatment for the disabled low-back pain patient. Spine 15:322-328, 1990

36. Lam KS, Carlin D, Mulholland RC: Lumbar disc high-intensity zone: the value and significance of provocative discography in the determination of the discogenic pain source. Eur Spine J 9: 36-41, 2000

37. Lindblom K: Diagnostic puncture of intervertebral discs in sciatia Acta. Orthop. Scand 17:231-239, 1948 (Reference unverified)

38. Lindblom K: Discography of dissecting transosseous ruptures of intervertebral discs in the lumbar region. Acta Radiol 36: 13-16, 1957 (Reference unverified)

39. Linson MA, Crowe $\mathrm{CH}$ : Comparison of magnetic resonance imaging and lumbar discography in the diagnosis of disc degeneration. Clin Orthop 250:160-163, 1990

40. Loneragan R, Khangure MS, McCormick C, et al: Comparison of magnetic resonance imaging and computed tomographic discography in the assessment of lumbar disc degeneration. Australas Radiol 38:6-9, 1994

41. Maezawa S, Muro T: Pain provocation at lumbar discography as analyzed by computed tomography/discography. Spine 17: 1309, 1992

42. McCarron RF, Wimpee MW, Hudkins PG, et al: The inflammatory effect of nucleus pulposus. A possible element in the pathogenesis of low-back pain. Spine 12:760-764, 1987

43. McCutcheon ME, Thompson WC III: CT scanning of lumbar discography. A useful diagnostic adjunct. Spine 11:257-259, 1986

44. Merskey H, Bogduk N (eds): Classification of Chronic Pain: Descriptions of Chronic Pain Syndromes and Definition of Pain Terms, ed 2. Seattle: IASP Press, 1994, p 178

45. Milette PC, Fontaine S, Lepanto L, et al: Differentiating lumbar disc protrusions, disc bulges, and discs with normal contour but abnormal signal intensity. Magnetic resonance imaging with discographic correlations. Spine 24:44-53, 1999

46. Moneta GB, Videman T, Kaivanto K, et al: Reported pain during lumbar discography as a function of anular ruptures and disc degeneration. A re-analysis of 833 discograms. Spine 19: 1968-1974, 1994

47. Ninomiya M, Muro T: Pathoanatomy of lumbar disc herniation as demonstrated by computed tomography/discography. Spine 17:1316-1322, 1992

48. Olmarker K, Byrod G, Cornefjord M, et al: Effects of methylprednisolone on nucleus pulposus-induced nerve root injury. Spine 19:1803-1808, 1994

49. Olmarker K, Rydevik B, Nordborg C: Autologous nucleus pulposus induces neurophysiologic and histologic changes in porcine cauda equina nerve roots. Spine 18:1425-1432, 1993

50. Perkins PG: Lumbar discography. J Neurosurg 65:882-883, 1986 (Letter)

51. Recommendations for lumbar discography in Int Spinal Inject Soc 2:80, 1997 (Reference unverified)

52. Resnick DK, Malone DG, Ryken TC: Guidelines for the Use of Discography for the Diagnosis of Painful Degenerative Lumbar Disc Disease. Neurosurg Focus 13(2):Article 12, 2002

53. Sachs BL, Vanharanta H, Spivey MA, et al: Dallas discogram description. A new classification of CT/discography in lowback disorders. Spine 12:287-294, 1987

54. Saifuddin A, Braithwaite I, White J, et al: The value of lumbar 
spine magnetic resonance imaging in the demonstration of anular tears. Spine 23:453-457, 1998

55. Schellhas KP, Pollei SR, Gundry CR, et al: Lumbar disc highintensity zone. Correlation of magnetic resonance imaging and discography. Spine 21:79-86, 1996

56. Schneiderman G, Flannigan B, Kingston S, et al: Magnetic resonance imaging in the diagnosis of disc degeneration: correlation with discography. Spine 12:276-281, 1987

57. Segnarbieux F, Van de Kelft E, Candon E, et al: Disco-computed tomography in extraforaminal and foraminal lumbar disc herniation: influence on surgical approaches. Neurosurgery 34:643-648, 1994

58. Simmons JW, Aprill CN, Dwyer AP, et al: A reassessment of Holt's data on: "The question of lumbar discography." Clin Orthop 237:120-124, 1988

59. Simmons JW, Emery SF, McMillin JN, et al: Awake discography. A comparison study with magnetic resonance imaging. Spine 16 (Suppl 6):S216-S221, 1991

60. Spiliopoulou I, Korovessis P, Konstantinou D, et al: IgG and IgM concentration in the prolapsed human intervertebral disc and sciatica etiology. Spine 19:1320-1323, 1994

61. Vanharanta H, Guyer R, Ohnmeiss DD, et al: Disc deterioration in low-back syndromes. A prospective, multi-center CT/discography study. Spine 13:1349-1351, 1988

62. Vanharanta H, Sachs BL, Ohnmeiss DD, et al: Pain provocation and disc deterioration by age. A CT/discography study in a lowback pain population: Spine 14:420-423, 1989

63. Vanharanta H, Sachs BL, Spivey MA, et al: The relationship of pain provocation to lumbar disc deterioration as seen by CT/ discography. Spine 12:295-298, 1987

64. Walsh TR, Weinstein JN, Spratt KF, et al: Lumbar discography in normal subjects. A controlled, prospective study. J Bone Joint Surg Am 72:1081-1088, 1990

65. Weinstein J, Claverie W, Gibson S: The pain of discography. Spine 13:1344-1348, 1988

66. Willburger RE, Wittenberg RH: Prostaglandin release from lumbar disc and facet joint tissue. Spine 19:2068-2070, 1994

67. Wise RE, Gardner WJ, Hosier RB: X-ray visualization of the intervertebral disc. N Engl J Med 257:6-10, 1957 (Reference unverified)

68. Zdeblick TA: A prospective, randomized study of lumbar fusion. Prelimary results. Spine 18:983-991, 1993

Manuscript received June 25, 2002.

Accepted in final form July 23, 2002.

Address reprint requests to: Frank J. Tomecek, M.D., 1919 South Wheeling \#600, Tulsa, Oklahoma 74104. 